\title{
The Genetics of Cancer*
}

\section{By Prof. J. B. S. Haldane, F.R.s.}

$\mathrm{T}$ HE statement is occasionally made, and as frequently denied, that cancer is hereditary. It is, of course, clear that environmental influences can play a leading part in determining the production of cancer.

The question is whether nature, as well as nurture, is of importance. By far the most satisfactory evidence on this point comes from a study of genetically homogeneous populations of mice. By brother-sister mating for many generations (more than fifty in certain cases) pure lines can be built up in which the individuals are all homozygous for the same genes, apart from rare cases of mutation. By crossing two pure lines we obtain a population which is also genetically uniform, but not homozygous. Their progeny, however, is not genetically uniform.

In such a population, we can study three types of cancer :

(l) due to transplantation of a tumour from another animal.

(2) due to a carcinogenic agent. These include tar, the hydrocarbons shown to be carcinogenic by Kennaway and his colleagues, certain parasitic worms, and $\mathrm{X}$-rays.

(3) spontaneous tumours; that is, tumours arising for no, at present, assignable cause.

Now the order of ease of study is the above. An inoculated tumour can be judged as a 'take' or otherwise within a month. Tar painting may produce tumours within six months; but spontaneous tumours in many lines do not reach their maximum incidence until an age of eighteen or more months. Hence our knowledge of tumour etiology is in the above order, though the order of practical importance for medicine is clearly the reverse.

It may be said at once that there are enormous differences between different lines as regards all three types of cancer. The genetics of reaction to transplantable tumours have been very fully worked out by Little and his colleagues. The laws disclosed are precisely similar to those which govern the transplantation of normal tissue or the transfusion of blood or of leukæmic corpuscles. A tumour arising spontaneously in one member of a pure line can be transplanted into all other members of it (actually more than 99 per cent of successful 'takes' can be achieved). Further, it can be transplanted into every $F_{1}$ mouse one of whose parents belonged to the pure line, but if these are mated together or outcrossed, only a minority of their offspring are susceptible. This at once suggests that susceptibility is due to the possession of certain dominant genes. This theory is fully confirmed by experiment. Supposing that a line $X$ carries $n$ pairs of genes $A A B B C C \ldots$

- Substance of lectures delivered at the Royal Institution on February 2 and $9,1933$. which are needed for tumour growth, and are not found in a line $Y$, then the $F_{1}$ will be $A a B b C c \ldots$, and 100 per cent susceptible. Of the back-cross from mating of the $F_{1}$ with $Y$, only $\left(\frac{1}{2}\right)^{n}$ will carry all $n$ genes, and of the $F_{2},\left(\frac{3}{4}\right)^{n}$ will carry them, and thus be susceptible. In a number of cases, Cloudman $^{1}$ found that the two values of $n$ so calculated were in agreement. The number of genes ranged from 2 to about 12 .

Similarly, a tumour arising spontaneously in a $F_{1}$ individual, between two pure lines, in general requires in its host $m$ genes contributed by one parent, and $n$ contributed by the other. In such cases the tumour will grow in all the $F_{1}$, in $\left(\frac{1}{2}\right)^{m}$ of one back-cross, $\left(\frac{1}{2}\right)^{n}$ of the other, and $\left(\frac{3}{4}\right)^{m+n}$ of the $F_{2}$. Thus Bittner ${ }^{2}$ found in one case $m=4, n=1$, while the observed value of $m+n$ was 5 .

Occasionally a tumour in the course of transplantation changes its character, so that it becomes transplantable into a larger proportion of a mixed population ( $F_{2}$ or back-cross). It is then found that one or more genes less are required for susceptibility in the host.

These facts can be explained if the host only reacts to a transplanted tumour so as to destroy it as the result of foreign antigens in that tumour, just as a recipient agglutinates the corpuscles of a donor if they carry foreign isoagglutinogens. On this hypothesis each gene is responsible for the manufacture of a particular antigen, as in the case of the red corpuscles. However, the genetical facts are quite independent of this hypothesis.

A thorough study of these phenomena is under way in Little's laboratory. The genes required for susceptibility to different tumours are being compared. Thus it was found that a number of tumours arising in the same line required the same basic gene for susceptibility, but each demanded a different assortment of extra genes. Some of these genes have been located, by means of linkage studies, in the same chromosomes as genes responsible for colour differences.

The tendency to develop cancer as the result of tarring varies greatly in different lines. Thus Lynch $^{3}$ compared two lines $A$ and $B$ which differed in their spontaneous tumour rates, $A$ having a higher incidence of spontaneous lung cancer than $B$. These tumours, however, never appeared before the age of 15 months. By tarring a large area of skin between the ages of 2 and 6 months, she induced lung tumours before the age of 13 months in 85 per cent of line $A$, and 22 per cent of line $B$. The difference was $6 \cdot 3$ times its standard error. On crossing $A$ and $B$ she found 79 per cent susceptibility. The back-cross to $A$ gave 81 per cent susceptibility, while that to $B$ gave 39 per cent. These figures suggest that susceptibility is 
determined, among other things, by a number of dominant genes. Other workers have obtained essentially similar results. Their importance for non-genetical workers on cancer is considerable. It is clear that in comparing the efficacy of two different carcinogenic agents, far fewer mice need be used in a pure line than in a mixed population, and it is worth noting that the variance in a mixed population is only about halved when litter mates instead of individuals taken at random are used as controls.

In the same way, Curtis, Dunning and Bullock ${ }^{4}$ state that in the rat they have found that susceptibility to cancer, on infection with the cestode Cysticercus, is strongly inherited.

The problem of spontaneous cancer presents much greater difficulties. In no line can one obtain 100 per cent of deaths from cancer, because over the long period necessary, deaths from other causes cannot be prevented. But some idea of the conditions in a highly cancerous line can be obtained from the work of Murray ${ }^{5}$. In a particular inbred line, 1,938 females lived to be more than 7 months of age. Of these, 65 per cent died of mammary carcinoma, or were killed when severely affected with it. Above 80 per cent of deaths in females more than twelve months old were due to this cause. None survived for 23 months and probably none would have reached two years without cancer had all deaths from other causes been prevented.

In such a line we can observe the effects on spontaneous cancer of prophylactic measures. Thus of 198 females ovariotomised at 7 months, only 40 per cent died of mammary cancer, and one of these reached the age of 30 months. Still more striking is the fact that not a single operated female living beyond 22 months developed mammary cancer. It follows that in this stock the ovary plays an important part in the causation of mammary carcinoma. It is clear that a pure line (or the $F_{1}$ hybrids of two pure lines) furnish ideal material for the determination of factors in the environment favourable or otherwise to the development of cancer.

In contrast with such lines are others with an extremely low susceptibility to spontaneous tumours under ordinary laboratory conditions. A cross between such lines generally gives a hybrid generation with a cancer mortality nearly so high as that of the more susceptible line. Indications of linkage with colour genes have been obtained in one case.

It is important that the location of tumours is highly specific. One line has a high deathrate from mammary carcinoma in females only, and few tumours elsewhere. Another line has a heavy incidence of primary lung carcinomata in both sexes, and little mammary carcinoma. A third has few carcinomata of any kind, but sarcoma is not very rare. The genetics of spontaneous cancer will clearly be very complicated, and it is quite ludicrous to ascribe it to the activity of one gene, dominant or recessive.
Besides the work described above, a good deal has been done on stock which was not genetically homogeneous. From this work it is clear that, while a tendency to spontaneous cancer is hereditary, it is not due to a single gene, dominant or recessive, and also that a particular localisation of cancer may be hereditary. Thus Zavadskaia ${ }^{\circ}$ found 13 out of 45 tumours in the occipital region in one particular line, and only 1 out of 212 in other lines. But all work with genetically heterogeneous material is unsatisfactory, because any individual may die before reaching the cancer age, and no other individual will be of just the same genetical make-up. Hence really exact work is impossible.

In the same way, human cancer tends to 'run in families' to some extent, but precise analysis is only possible where, as with retinoblastoma and some sarcomata, its victims are attacked early in life. Here there is reason to believe that a single dominant gene is mainly responsible for the cancerous diathesis, though environmental and possibly other genetic factors may be concerned as well.

A particularly clear case of the interaction of nature and nurture in cancer production is found in the case of human xeroderma pigmentosum, almost certainly a recessive character. Here the skin becomes inflamed, and ultimately cancerous, under the influence of light. We could speak with equal logical propriety of the recessive gene or the light as the 'cause' of the cancer, but as the former is rare, and the latter universal, it is more natural to regard the cancer as genetically determined.

Thus we have evidence of many different types of genetical predisposition to cancer, and although the data available on mice suggest that this predisposition is generally due to multiple dominant genes, it would certainly be incorrect to apply this theory to all human types of malignant disease.

The theory has been held by Boveri, Strong, and others, that the difference between a cancer and a normal cell is of the same character as that between the cells of two different varieties, that is to say, due to chromosomal aberration or gene mutation. This theory cannot of course be proved or disproved by genetical methods, as cancer cells do not reproduce sexually, and it is only by sexual reproduction that the geneticist can distinguish nuclear changes from plasmatic changes or virus infections.

The geneticist is concerned with the differences of 'nature' (in Galton's sense of the word) which play their part, along with environmental differences, in determining whether a given animal will or will not develop cancer. $\mathrm{He}$ is not particularly qualified to determine whether the difference between a normal cell and a cancer cell is analogous to that between sister gametes produced at meiosis, or to the difference which comes about at other cell divisions in the course of differentiation. The recognition of the import- 
ance of genetics for the study of cancer need not lead to any decision on this point.

To sum up, we can devise conditions under which either nature or nurture will play a pre-. dominant part in determining the incidence of cancer. Neither factor can possibly be neglected in a comprehensive survey. Except in a few cases, such as retinoblastoma, our knowledge is not sufficient to warrant interference with human breeding on eugenic grounds. Nevertheless, it is probable that in the ultimate solution of the problem of human cancer, eugenical measures will play their part.

\footnotetext{
${ }^{1}$ Cloudman, A. M., Amer. J. Cancer, 16, 568; 1032.

Bittner, J. J., Amer. J. Cancer, 15, 2202 ; 1931.

- Lynch, C. J., J. Exp. Med., 46, 917; 1927.

- Curtis, Dunning and Bullock, Amer. Nat., 67, 73; 1933.

- Murray, W. S., Science, 75, 646; 1932.

- Zavadskaia, J. Genetics, 27, 181; 1933.
}

\section{Gem Stones*}

\section{By Prof. W. T. Gordon}

$\mathrm{T}$ HE first essential of a gem is that it should be beautiful and attractive, but if the beauty be ephemeral the gem will not command continued popularity. Occasionally an attractive colour in \& material will assume a paler tint, or vanish entirely, or even change to an opaque black shade. Or again, the surface may tarnish and all its beauty disappear. Change of colour, however, is not the only factor that may mar the glory of a beautiful substance. Lack of resistance to wear is very undesirable, particularly in transparent materials, and not all beautifully coloured minerals have the property of durability.

There is also a psychological factor that must not be omitted. Unless the material is rare it is little prized. Beauty therefore has to be accompanied by durability and rarity before popular opinion will consent to apply the term gem stone to any substance. The artistic and educated mind may resent this attitude, but vox populi is in this connexion vox dei, so far as monetary values and general acceptance of the term are concerned.

At the moment, however, beauty will be considered paramount, and there are several natural minerals that come into the category of gem stones. The methods adopted to display the maximum beauty are based on scientific principles, although these were nearly all discovered by the lapidary through experience, before they were formulated by the man of science. It is these laws and the methods adopted by the lapidary to secure their operation that will be considered here.

The natural minerals classed as gem stones may be opaque, translucent or transparent, and do not belong to any special category so far as their chemical composition is concerned : while one and the same material may occur in a great variety of colour and many degrees of transparency.

It seems probable that the earliest gems were attractively coloured substances with some degrce of lustre, that property depending on the intensity of the light reflected from the surface. Were that surface smoothed and polished, the lustre would be increased and the full value of the colour

- Friday evening discourse delivered at the Royal Institution on May 12. developed. As large continuous areas give the finest effects, curved surfaces were worked on the materials in order that the colour and lustre might be visible from any angle. The term cabochon is applied to this style of cutting, and the cabochon may be deep or shallow. When deep, the top surface may be ellipsoidal (oblate or of revolution) and is often called tallow-topped; when shallow, this term is not applied. 'The stone may have a flat base, a rounded base or a hollow base, and these styles are called cabochon, double cabochon, and hollow cabochon respectively. When the colour is deep and the material translucent, a hollow cabochon specimen is frequently lined with gold or silver foil on the hollow side, and the colour is much enhanced by light reflected through the stone, from the bright metal surface on the base.

Another class of gems, both opaque and translucent, exhibits a fibrous habit or has inclusions or even cavities, arranged in parallel series. If the fibres, inclusions or cavities are very delicate, and are set parallel to definite directions, light is reflected more intensely from the long edges of these, and a luminous zone or set of intersecting luminous zones is produced. Along with the natural colour of the material these bands of light produce an attractive appearance. Such stones are also cut in a rounded or oval form, and are termed cat's-eyes or star-stones according as there is one luminous band or three intersecting bands.

'Thus far the only scientific principles involved have been the formation of smooth, rounded shapes that will function in the reflection of light coming from any direction; and the larger the surface the better the effect.

The finest results of the lapidary's skill are seen, however, in the treatment of transparent gems, coloured or uncoloured, and the latter illustrate in the highest degree the skilful application of the principles of the refraction, reflection, dispersion and interference of light.

In coloured gems the beauty lies largely in that colour, whether the material be transparent or opaque; but, in colourless stones, the beauty must be developed by the skill of the artificer. A 